\title{
Oligopolio y estrategias de competencia en el mercado de minoristas en México
}

Oligopoly and competition strategies in the retail market in Mexico

Gustavo Vargas Sánchez *

Carlos Mario Rodríguez Peralta **

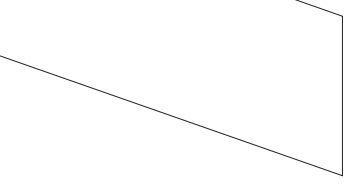

Resumen

El objetivo de este ensayo es hacer una aproximación a las formas de competencia y la dinámica microeconómica del mercado de las empresas minoristas en México. La hipótesis de la investigación es que este mercado no es de competencia perfecta, sino que opera como un mercado oligopólico, por lo que se ha supuesto que está dominado por pocas empresas, en donde se puede identificar a una líder y a otras más que se comportan como seguidoras. El precio no es fijado por las libres fuerzas del mercado sino por las corporaciones y su lucha por el mercado nacional, al desplegar una serie de complejas estrategias competitivas, donde se incluyen distintas combinaciones de variables que van más allá de sólo los precios. Las formas de competencia existentes en éste mercado pueden tomar diversas modalidades según sus estrategias y el estado de la competencia. Entre dichas variables podemos encontrar además de los precios, el servicio al cliente; las innovaciones; variedad de productos ofrecidos; segmentación de mercado; calidades de productos e infraestructura en el piso de ventas; fusiones, adquisiciones y asociaciones. Finalmente se puede suponer un comportamiento oligopólico concentrado donde destaca la existencia de una relación de interdependencia entre los jugadores de este mercado.

Algunas de estas hipótesis, fueron comprobadas, otras matizadas, pero la conclusión más importante es que el comportamiento de las empresas, los mercados y la competencia a nivel microeconómico es compleja y evoluciona en el tiempo.
* Profesor de Tiempo Completo, en el área de teoría económica y economía de la empresa. Facultad de Economía UnAM. Sus líneas de investigación son: Microeconomía aplicada, análisis micro y estrategias competitivas de las Grandes Corporaciones Mexicanas. vargassanchez01@live.como.mx

** Estudiante de Doctorado, Facultad de Economía unam. Profesor de Asignatura, Facultad de Economía unAm. Profesor de Asignatura UAEm. Sus líneas de investigación son: Industria Automotriz, Economía de la Empresa, Inversión, Redes Globales de Producción, Economía Internacional. cmrperalta@iden.mx

Palabras clave

Consumo, empresas, estructura de mercado, comercio minorista

Key words Consumption, Firm, Market Structure, Retail

JEL $E 21, H 32, L 1, L 81$ 


\section{ECONOMÍA INFORMA $\mid 400$ | SEPTIEMBRE-OCTUBRE 2016 |}

\section{Abstract}

The overall objective of this paper is to make an approach to the analysis about competition and microeconomic dynamic on Mexican retail market. The research hypothesis is that Mexican retail market is not a perfect competition case, because it operates as an oligopoly market. So, it is assumed that this market is dominated by a few companies, where it is possible identify a leader and other companies that behave as followers. The competition in this market can take different shapes according to the corporations' strategies. The price is not set by free market forces but tic market, in which companies deploy a set complex competitive strategies where different combinations of variables are included, variables that are not just prices. Among these variables we can find, besides price, customer service; innovations; variety of offered products; market segmentation; product quality and sales infrastructure; mergers, acquisitions and partnerships; etc. Finally we can observe a concentrated oligopolistic behavior which highlights the existence of interdependence relationships among players.

Some of these hypotheses were confirmed and nuanced, but the most important conclusion is that the behavior companies, markets and competition at the microeconomic level, are complex and evolves over time.

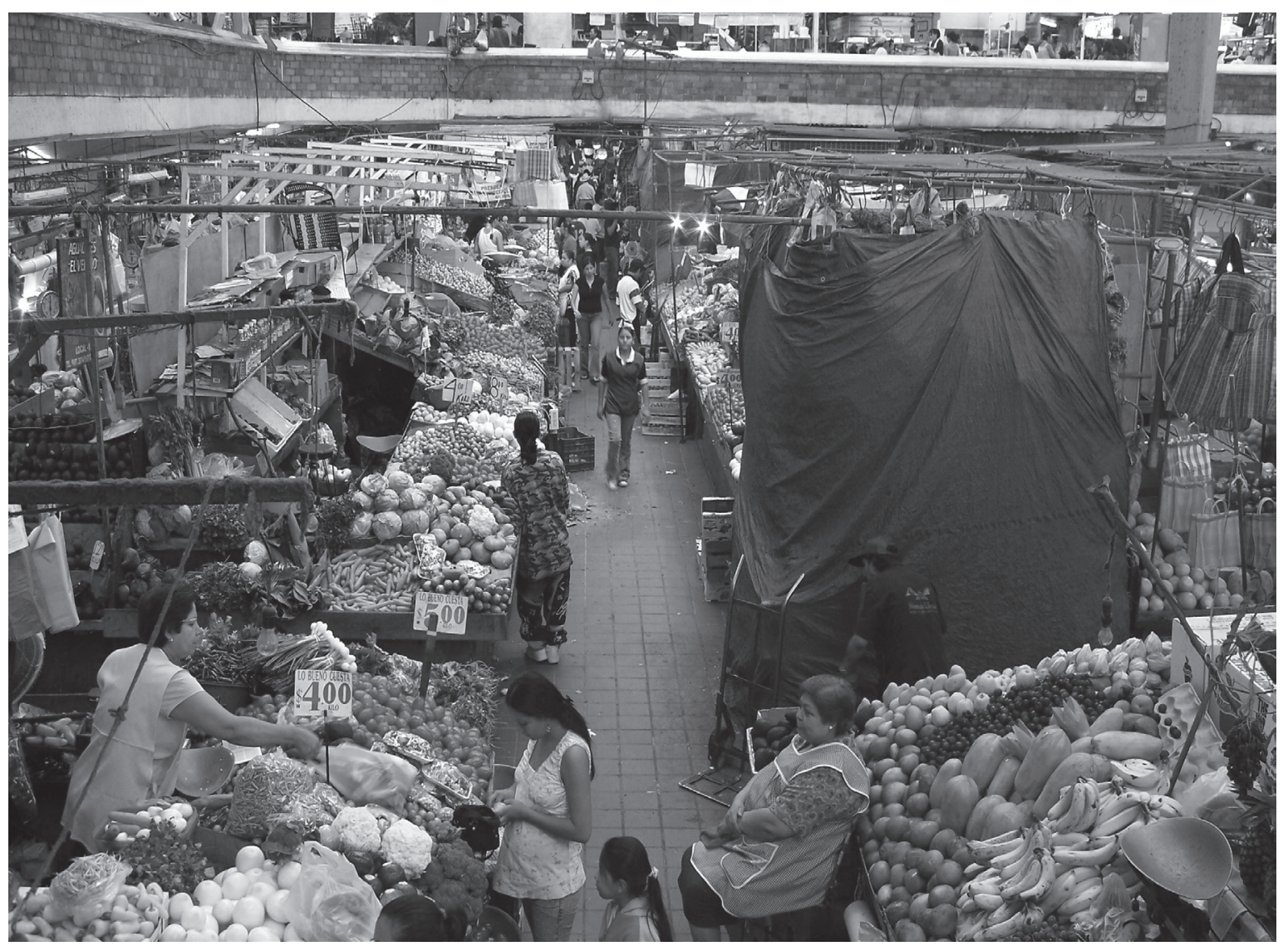


Gustavo Vargas Sánchez | Carlos Mario Rodríguez Peralta |

Oligopolio y estrategias de competencia en el mercado de minoristas en México

\section{Introducción}

El mercado minoristas es aquel en el cual se ponen a disposición del consumidor final distintos productos. Las transacciones individuales involucran bienes en cantidades que corresponden a la dotación necesaria para el consumidor individual o como familia, de forma agregada, la compra de los consumidores sigue en general la evolución de la demanda agregada nacional. Por el lado de la oferta, está conformado, por empresas comercializadoras que venden al por menor o al detalle y cuentan con una gran cantidad de recursos y capacidades tales como: capital financiero, organización, sistemas complejos de administración de la información y distribución nacional y global.

Se trata de un mercado dominado por grandes corporaciones que tiene por resultado la conformación de un mercado oligopólico que ha desarrollado un proceso de competencia complejo que cambia en el tiempo.

El mercado (de minoristas) tiene un significado distinto al que posee el concepto de mercado de la teoría tradicional, donde se encuentran oferentes y demandantes. En el mundo real existen intermediarios, los cuales desarrollan sistemas complejos de distribución, organización, información y ventas.

En el mercado minorista participan empresas comercializadoras micro, pequeñas, medianas y gigantes o mega-corporaciones con un poder de mercado local, regional, nacional e incluso global. El minorista posee un lugar estratégico: se encuentra en el centro de la cadena producción-consumo beneficiándose de la ventaja de su posición al ser el medio de contacto entre productores y consumidores. Por un lado, con respecto a los productores cuenta con una gran capacidad de compra, para influir en los precios y calidad de los productos de las empresas. Y por otro lado, con respecto a los demandantes, cuenta con la capacidad de fijar el precio, éstos se comportan como precio y calidad aceptantes.

\section{Enfoque teórico}

La empresa es una organización cuyo objetivo es crear beneficios monetarios a través de la producción y venta de bienes y servicios (E. Penrose, 1958), y su característica principal es que evoluciona y crece a lo largo del tiempo. Es una entidad dinámica que posee varias características adicionales: es una organización jerárquica, con una dimensión histórica e institucional. Posee un papel dinámico en el mercado y desarrolla estrategias de todo tipo para vender sus productos, crecer, y dominar su mercado (Lee, 1988; Chandler, 1969; Penrose 1958). La empresa, por tanto, consiste en una organización dinámica sujeta a una ley de expansión y crecimiento. Los precios y las cantidades son relevantes en cuanto al papel que tienen en el proceso de creación y distribución de ingresos con el objetivo final de crecer (Andrews, 1959; Eichner, 1988; Lavoie, 1992; Vargas, 2006a).

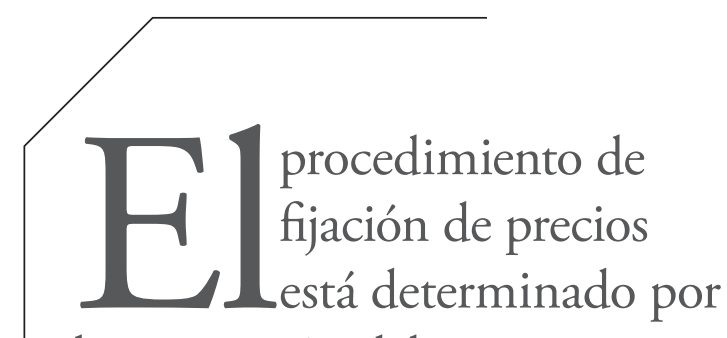

la estimación del precio a partir de los costos de la empresa más un margen de ganancia o mark-up 
La empresa relevante en la época actual del capitalismo es la mega-corporación, la cual es una organización compleja que está en continuo crecimiento y tiene poder para determinar sus precios. La mega-corporación en una industria oligopólica posee el poder suficiente para fijar el precio y la capacidad de gestionar los procesos de financiamiento de la empresa para su expansión y crecimiento constante (Eichner, 1988; Vargas 2006b).

El mercado de producción capitalista está dominado por esas grandes corporaciones, cuyas decisiones influyen y afectan el comportamiento de las otras empresas y a los consumidores. Los otros participantes del oligopolio reaccionan a las acciones de sus rivales. El procedimiento de fijación de precios está determinado por la estimación del precio a partir de los costos de la empresa más un margen de ganancia o mark-up. Este procedimiento considera no solo los precios, sino además: los planes de inversión y expansión, es decir, la necesidad de fondos adicionales de inversión, el estado de competencia de su mercado donde juegan las barreras a la entrada, la amenaza de competidores, las innovaciones, y las posibilidades de intervención del Estado (Eichner, 1988: 32).

Adicionalmente, dentro de un oligopolio, además de una o dos grandes empresas con capacidad para controlar el mercado, pueden coexistir, medianas y pequeñas empresas que también participan en la industria, y todas las empresas se benefician de esa estructura (Labini, 1966).

Por otro lado, las innovaciones juegan un papel importante en la estrategia de competencia de las grandes empresas oligopólicas, pues ésta les ofrece una ventaja sobre sus rivales, consistente en la generación de una ganancia asociada a la innovación, una ganancia a la que solo el innovador tiene acceso, aumentando el margen de ganancia previo de la empresa, colocándola en una trayectoria de crecimiento que a su vez le permitirá sentar las bases para generar más innovación (Schumpeter, 1912, Labini, 1966: 165).

Los mercados oligopólicos, tendrán la característica general y distintiva de albergar la existencia de una empresa que se perfila como líder (Eichner, 1988), aquella que por sus características como tomadora de riesgos e innovadora, ha logrado capturar una mayor participación en el mercado. Dicha posición le permite contar con mayores beneficios que puede incluso reinvertir para mantener su posición como líder. Sin embargo, está siempre bajo la presión de otras grandes empresas, las seguidoras, que aunque poseen menor participación en el mercado, luchan por arrebatarle su posición como líder. Se trata se trata de una relación dinámica líder-seguidoras en donde todas ellas son empresas rivales que compiten en un mismo mercado. La posición de la líder está, además, basada en su capacidad de generar innovaciones que no son susceptibles de ser copiadas fácilmente, y en la medida que lo logre, será la capacidad que posee para mantenerse como tal (Kaplinsky, 2005).

En un mercado en donde la brecha entre la empresa líder y las seguidoras sea menor, y por tanto la competencia por arrebatarse el liderazgo sea mayor, la inversión tendería a ser mayor que en un mercado en donde la brecha entre líder y seguidoras sea mayor y por tanto, la presión de las seguidoras sobre la líder sea menor. En síntesis, el corazón del sistema capitalista está en la empresa y sus relaciones dinámicas con el mercado. 
Gustavo Vargas Sánchez | Carlos Mario Rodríguez Peralta |

Oligopolio y estrategias de competencia en el mercado de minoristas en México

\section{Estructura y evolución del mercado de minoristas en México}

En México el mercado de minoristas está dominado por Walmart, Chedraui, Comercial Mexicana y Soriana. Dichas empresas concentran $80 \%$ del mercado. La oferta de estas empresas consiste en una amplia variedad de productos que van desde alimentos, bebidas, artículos de limpieza, hasta muebles, electrónicos, juguetes y accesorios. La competencia en éste mercado posee diferentes formas que aquí se intentan analizar. Las tiendas departamentales y de conveniencia, a pesar de ser parte de un más amplio mercado de minoristas, no se incluyen en este análisis.

En el mercado de minoristas, cada uno de los jugadores ha tratado de crecer y dominar el mercado, o de

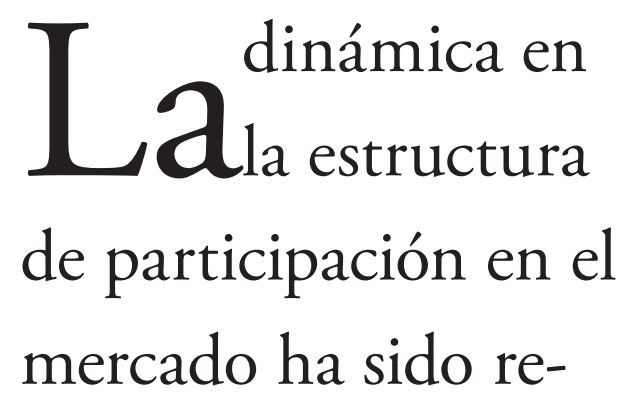

sultado de diferentes

estrategias de compe-

tencia de la empresa

líder y la respuesta de

las seguidoras. na. Sus estrategias le han permitido mantener $18 \%$ de la participación del mercado (2006), y en 2014 reporta 15\%. En 2015 adquirió parte de Comercial Mexicana, por lo que su participación aumentará notablemente. Chedraui por su parte ha logrado aumentar su participación en el mercado hasta un $11 \%$ para 2014. Comercial Mexicana en esta guerra ha sido la perdedora, en 2014 representó $7 \%$ en el mercado de minoristas (véase cuadro 1). sobrevivir en el mismo. La penetración de las cadenas minoristas en el mercado nacional y en el consumo de los mexicanos ha aumentado notablemente, y la disputa por el mercado ha sido fuerte. La ganadora indiscutible en éste mercado ha sido Walmart, pues en el periodo de 1999 a 2014 paso de ocupar 52 a 67\% del mercado nacional. Muy por detrás, Soriana se ha colocado como la seguidora más cerca-
La dinámica en la estructura de participación en el mercado ha sido resultado de diferentes estrategias de competencia de la empresa líder y la respuesta de las seguidoras.

Para entrar al mercado mexicano Walmart llevó a cabo alianzas y adquisiciones: en el 2000, luego de una alianza estratégica absorbió totalmente a Grupo Cifra (Aurrera). Al mismo tiempo creó marcas propias como Great Value y Equate, e impulsó el incremento de formatos de Bodega Aurrera.

En 2001 Walmart ya había desarrollado una estrategia de competencia a través de diferenciación de formatos en sus tiendas (en aquel año ya contaba con 4 formatos). Esta fue una de las estrategias que le permitiría avanzar en su participación en el mercado y debido a su éxito, fue reproducida por las otras tiendas, principalmente por Soriana. 
Soriana mantuvo su participación de mercado en $18 \%$ gracias a sus planes de expansión, logrando duplicar el número de tiendas y su expansión hacia la Ciudad de México. Soriana como seguidora reprodujo la estrategia de formatos de tiendas orientados a diferentes estratos de ingresos de la población que Walmart implementó. En esta misma dirección Comercial Mexicana en 2006 exploró un nuevo segmento de mercado asociado a las clases de ingresos más altos: las tiendas City Market. Dichas tiendas han resultado altamente rentables, al igual que las tiendas Fresko en 2009, por lo que la empresa, después de la venta de sus formatos insignia a Soriana, ha decidido conservarlas (además del formato Sumesa, planeando reconvertirlos en sus otros formatos próximamente).

La participación de mercado de Chedraui aumenta un punto porcentual pero lo suficiente para permitirle sobrevivir ante la fuerte competencia. Parte de su estrategia fue la de crecer por adquisiciones: en 2005 adquirió 29 tiendas de la empresa francesa Carrefour, quién decidió retirarse del mercado mexicano.

\section{Cuadro 1}

Evolución porcentual de la participación de las 4 principales empresas minoristas en México (1999-2014) (en porcentajes)

\begin{tabular}{ccccc}
\hline & Walmart & Soriana & Chedraui & Comercial \\
\hline 1999 & 52 & 18 & 8 & 23 \\
2001 & 55 & 18 & 6 & 21 \\
2006 & 60 & 18 & 9 & 14 \\
2014 & 67 & 15 & 11 & 7 \\
\hline
\end{tabular}

Fuente: elaboración propia en base a Estados de Resultados de las respectivas empresas, extraídos de Economática. Nota: 2014 no incluye la compra de Comercial Mexicana por parte de Soriana ni las ventas de sus tiendas.

\section{La demanda del mercado de minoristas en México}

La demanda muestra un desempeño muy dinámico, lo cual ha favorecido la expansión de las grandes cadenas comerciales en México. En la gráfica 1 podemos apreciar que el desempeño de las ventas de la empresa líder Walmart, es más dinámico que la evolución del Producto Interno Bruto (PIB) de la economía mexicana. Esta es una característica del crecimiento de las empresas líderes que se convierte en oligopolios en los diferentes mercados y ha sido señalado en la teoría de la empresa (Penrose, 1958).
El desempeño de las ventas de las empresas minoristas en general está determinado por tres factores claramente identificables: $a$ ) la expansión de la demanda a nivel nacional, b) La estructura de ingresos de las clases sociales y su correspondiente poder de compra, y c) la misma estructura de competencia tanto entre las minoristas, como de estas en contra de los detallistas más pequeños. En la gráfica anterior se muestra claramente la relación que existe entre las ventas y el PIB nacional. En los últimos años su crecimiento ha sido destacable sobre todo en un contexto nacional en que el crecimiento es lento. En la expansión de las grandes cadenas minoristas, el margen de utilidad con el cual trabajan ha sido un estímulo para su expansión. 
Gustavo Vargas Sánchez | Carlos Mario Rodríguez Peralta |

Oligopolio y estrategias de competencia en el mercado de minoristas en México

Gráfica 1 PIB y ventas de minoristas (Walmart) 1999-2014 (2000=100)

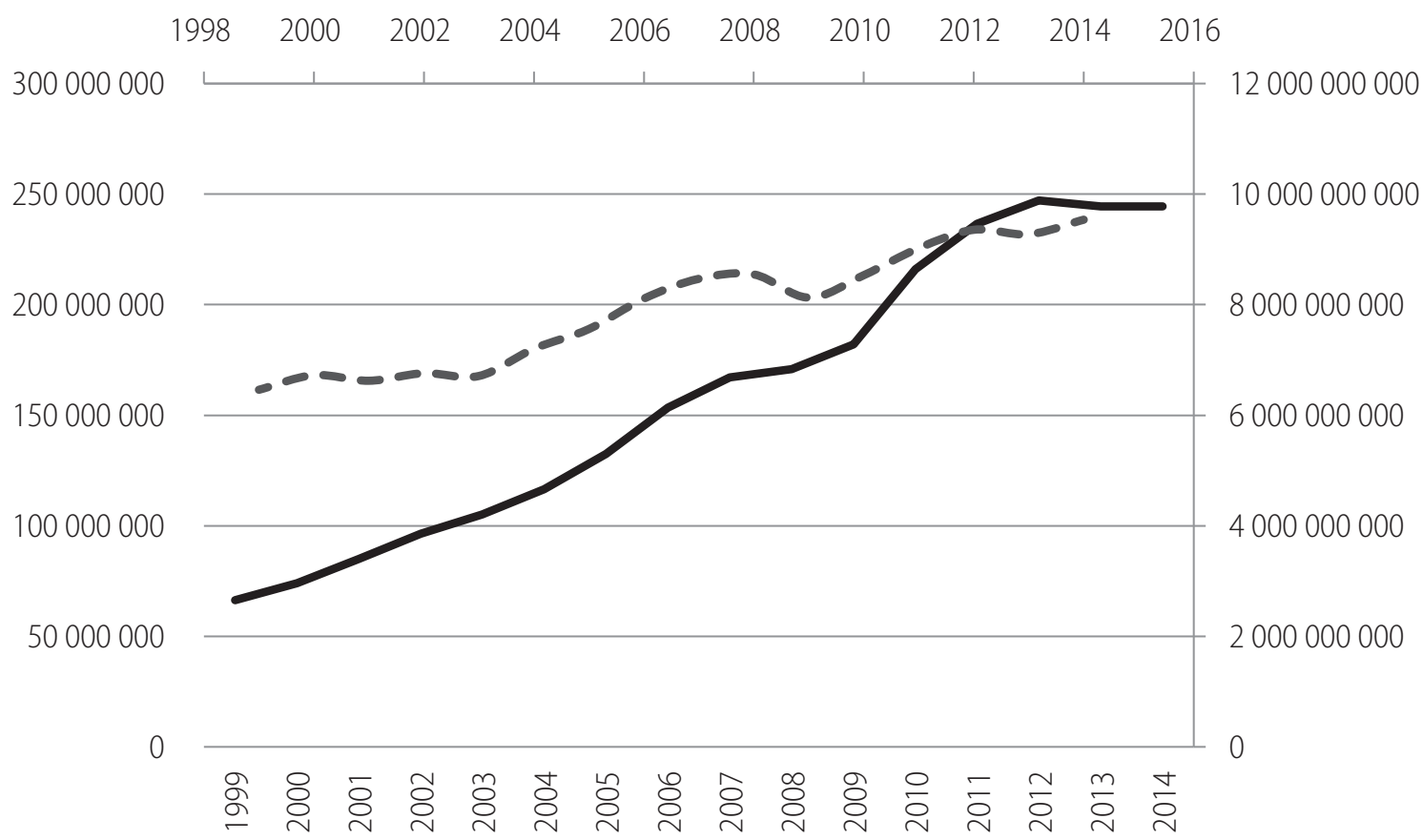

Ventas Walmart Base 2000=100

- - PIB México Real Base 2000=100

Fuente: de PIB e INPC: INEGI. Sistema de Cuentas Nacionales de México. Fecha de consulta: 13/02/2016. Y Minoristas, Elaboración propia en base a datos de Wal-Mart, Soriana, Chedraui y Comercial Mexicana Estado de Resultados/Economática. 


\section{Evolución de la oferta del mercado de minoristas en México}

La oferta presenta varias características destacables: en primer lugar ha tenido un desempeño muy vigoroso, mostrado por su notable crecimiento de su capacidad de oferta.

La gráfica 2 muestra cómo el desempeño de la oferta de las minoristas (aproximada por la superficie de ventas) sigue muy de cerca el desempeño del pis de la economía nacional. También se puede interpretar como que la estrategia de oferta de la minorista líder (como representativa de la oferta de las otras empresas) sigue de cerca el desempeńo de la demanda agregada nacional (recuerde que en una si- tuación de equilibrio del sector externo, el pIB es igual a consumo privado, más consumo de gobierno, más formación bruta de capital fijo).

En algunos años el crecimiento de las ventas de las minoristas ha tenido en desempeńo superior al del piв nacional. Por ejemplo, en 2015 mientras el pIB crecía en menos del $2.5 \%$, las ventas de enero a enero crecieron, según datos de la Asociación Nacional de Tiendas de Autoservicio y Departamentales A. C. (ANTAD), en casi 9\%, y en cuanto a las ventas totales alcanzaron un crecimiento de $10.3 \%$ (Milenio, 14-02-16).

Por otro lado, a medida que crece la capacidad de oferta de las grandes minoristas medido por su creciente número de tiendas, cualquiera que sea la cadena comercial y su formato, tiene

\section{Gráfica 2 \\ PIB y superficie de piso de ventas de Walmart de México $\left(\mathrm{m}^{2}\right)$ 2006-2014 (Millones de pesos de 2000)}

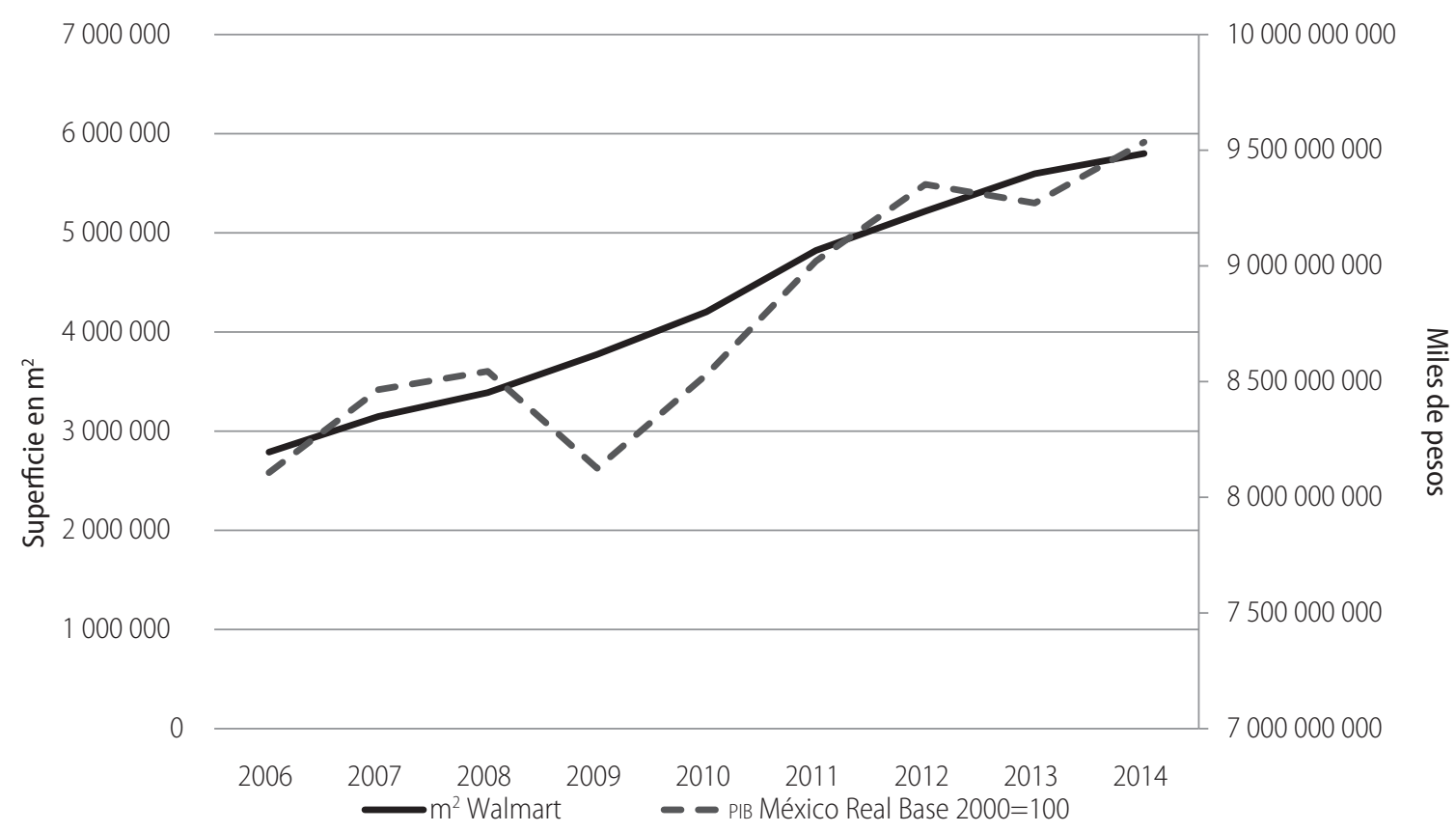

Fuente: elaboración propia en base a Estado de Resultados Wal-Mart en Economática e informe anual 2014 en su página http://www.walmex.mx/es/informacion-financiera/anual.html.Fuente de PIB e INPC: INEGI. Sistema de Cuentas Nacionales de México, fecha de consulta: 13/02/2016. 
Gustavo Vargas Sánchez | Carlos Mario Rodríguez Peralta |

Oligopolio y estrategias de competencia en el mercado de minoristas en México

\section{Gráfica 3 Evolución de la superficie de ventas en miles de metros cuadrados, 2009-2014}

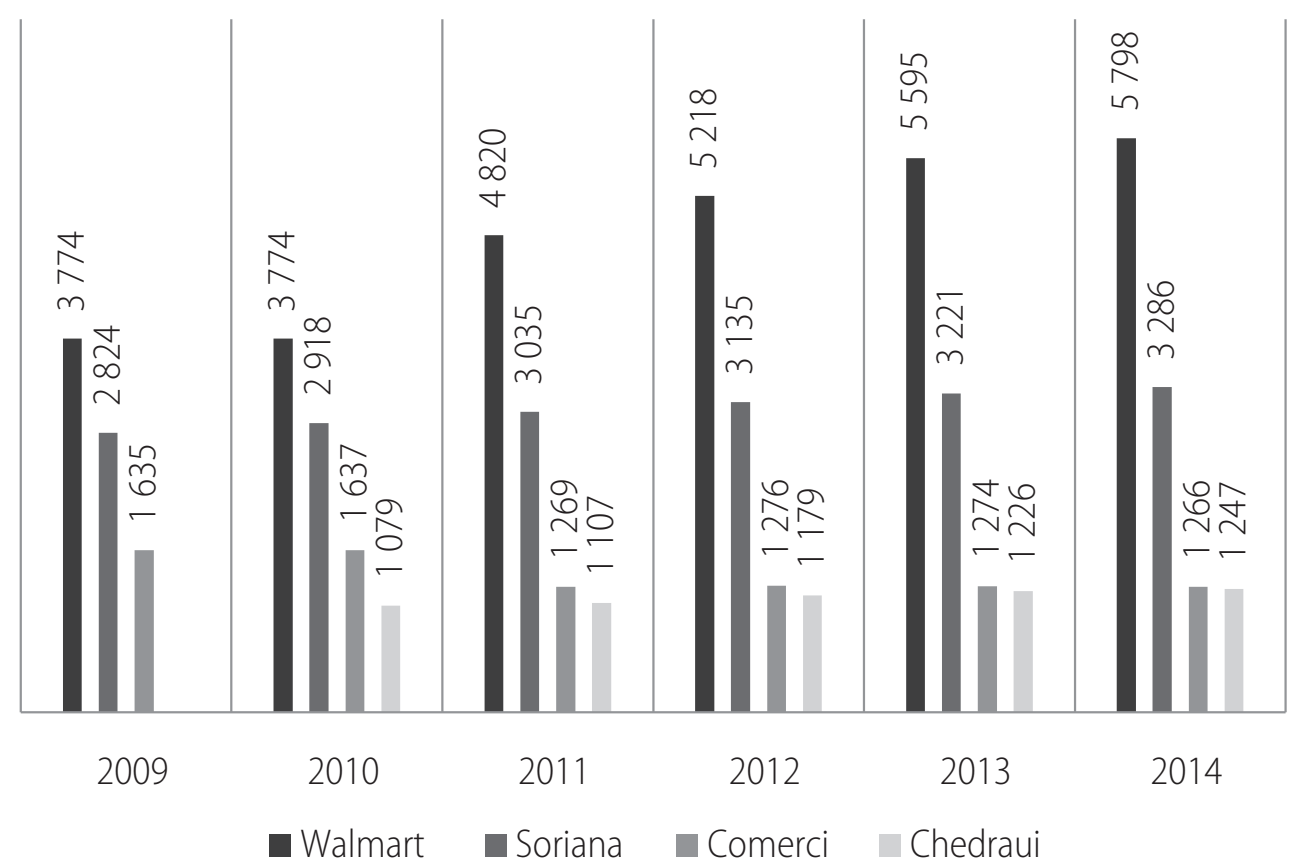

Fuente: elaboración propia en base a informes anuales de Wal-Mart de México en su página: http://www.walmex.mx/ es/informacion-financiera/anual.html; Comercial Mexicana: http://www.comerci.com.mx/index.php?option=com content\&view=article\&id=90\&ltemid=52\&lang=es; Organización Soriana:http://www.sorianadomicilio.com/ site/default.aspx?p=2946; Grupo Chedraui: http://chedrauiv4.random-interactive.com/index.php?r=site/ rendercontent\&content=pages/historia

como consecuencia la presión al cierre de muchas de las tiendas tradicionales que se encuentran a su alrededor.

La gráfica 3 muestra el crecimiento de la superficie de ventas de las cuatro principales minoristas en México. Es claro que Walmart es la líder no solo en ventas sino en su capacidad de ventas, pues si bien en 2013 redujo su superficie, en 2014 regresa al crecimiento. Soriana se coloca como la seguidora más importante, aunque representa solo un poco más de la mitad de la superficie de la líder. Dicha brecha se ha de reducir, pues en 2015 se anunció la compra que por parte de Soriana de 143 tiendas Comercial Mexicana. Para 2015 esta última cadena reportará una caída considerable en la superficie de ventas, quedando relegada al cuarto y último lugar. Por su parte Chedraui que ha reportado un crecimiento muy lento, casi de sobrevivencia ocupará el tercer lugar.

En cuanto a unidades de ventas, la tendencia de la oferta es claramente creciente, Walmart ha dominado pasando de 2009 a 2014 de 1472 a 2163 unidades. Este ritmo de expansión, pero en menor escala, solo lo ha podido seguir Soriana, que en el mismo periodo pasó de 471 a 674 unidades de venta. Comercial Mexicana, por su parte, durante estos años no se ocupó de su crecimiento en este renglón, probablemente debido a su proceso de saneamiento de sus finanzas corporativas resultado de su crisis en 2009. Comercial Mexicana hoy 


\section{Gráfica 4 Unidades de venta de los minoristas en México (2009-2014)}

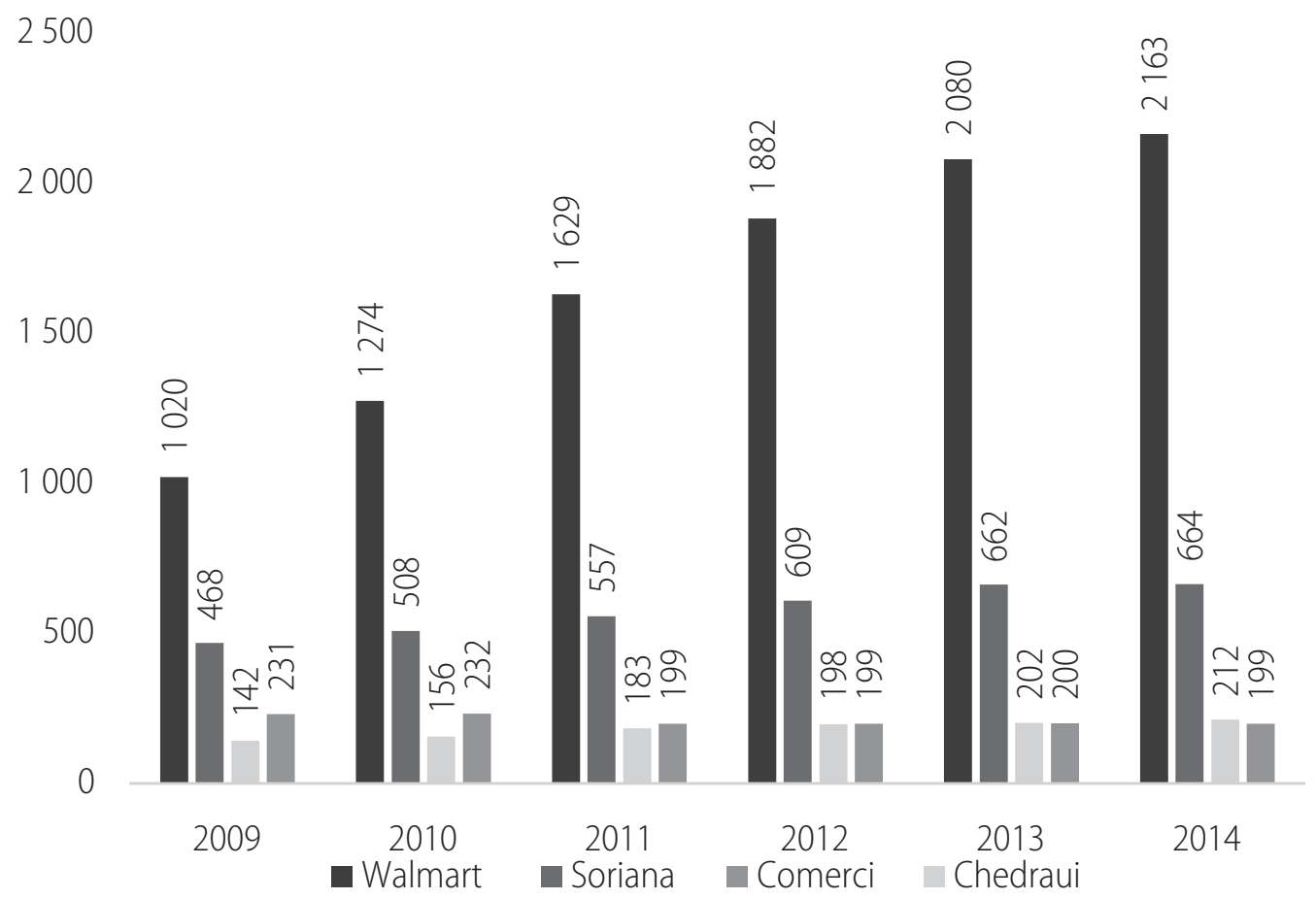

Fuente: elaboración propia en base a informes anuales de Wal-Mart de México en su página: http://www.walmex.mx/ es/informacion-financiera/anual.html; Comercial Mexicana: http://www.comerci.com.mx/index.php?option=com_ content\&view=article\&id=90\&ltemid=52\&lang=es; Organización Soriana:http://www.sorianadomicilio.com/ site/default.aspx?p=2946; Grupo Chedraui: http://chedrauiv4.random-interactive.com/index.php? $r=s i t e /$ rendercontent\&content=pages/historia

trata de explotar un segmento de ingresos altos que le es muy rentable. Por su parte, Chedraui también reporto un incremento porcentual significativo de sus unidades de ventas. El resultado de la competencia en este mercado ha desembocado en su concentración en tres grandes jugadores.

\section{Formas de competencia}

Con la entrada de Walmart al mercado mexicano se ha desarrollado un juego de interdependencia entre los jugadores, donde las estrategias de la empresa líder trataron de ser imitadas por sus competidores.
La estrategia de Walmart desde su entrada al mercado mexicano se ha basado en su gran poder financiero y de inversión no sólo por la compra de Cifra, sino por su acelerado proceso de inversión en nuevas unidades de venta. En dicha estrategia de competencia destaca su red de proveedores a nivel nacional y global. En esta relación destaca su poder de negociación con éstos últimos para fijar precios, un poder que se asemeja a una estructura de monopsonio. Destaca la capacidad de sus sistemas de logística, comercialización y sistemas automatizados de distribución. En cuanto a sus clientes la estrategia seguida fue la creación de diferentes formatos de tiendas, lo que le implicó un esfuerzo de inversión muy costo- 
so. Con respecto a la relación laboral con sus trabajadores por una parte, les ofreció mejores salarios y condiciones de trabajo que sus rivales pero siempre con el control del sindicato. Las estrategias de Walmart y su crecimiento dieron lugar a una competencia de inversión y crecimiento muy variado de las cadenas minoristas en el mercado nacional. En un análisis de largo plazo y dinámico, el esfuerzo de inversión es una fuerza, o tal vez la más poderosa, de la competencia en los mercados oligopólicos.

\section{Las fusiones, adquisiciones y asociaciones}

Una de las formas de crecimiento y competencia clásica en todos los mercados ha sido la de fusiones y adquisiciones. Esta es una forma de competencia de "no precios", más bien de inversión, que ha demostrado éxito en el mercado minorista: cuando Walmart decide entrar al mercado mexicano, lo hizo primero a través de una alianza en 1991 con Cifra, para transformarlo ańos más tarde en un proceso en el que la empresa minorista más grande de USA adquiría a la cadena de minoristas más grande de México. Esta adquisición inició con una alianza estratégica entre ambas empresas, la cual serviría para la introducción de la marca Walmart en México, y sobre todo, para que la minorista extranjera conociera el mercado local. Posteriormente la alianza se transformaría en 1997 en una Joint Venture y, tres años después, Walmart Stores Inc. adquiriría completamente a la cadena mexicana creando con este proceso a Walmart de México en el año 2000.

Las otras compañías de autoservicio en México enfrentaron una muy fuerte amenaza, ninguna de las cadenas existentes contaba con el alcance del mercado nacional ni la potencia económica de Walmart. Las cadenas nacionales solamente tenían una influencia regional: Comercial Mexicana y las tiendas Gigante (minorista que habría de ser eliminada del mercado en la intensa competencia) dominaban en la región centro, Soriana dominaba en las regiones norte y noroeste, y Chedraui en el sur del país. Hoy en día las cadenas nacionales han intentado superar la barrera regional, pero sus principales mercados siguen siendo los mismos.

Ante la fuerte competencia que representó Walmart, en 2003 las cadenas nacionales: Soriana, Comercial Mexicana y Gigante establecieron una alianza que duraría hasta 2008. La alianza, que no significó la pérdida de la independencia de cada una de las empresas involucradas, buscaba: $a$ ) incrementar en conjunto, sus capacidades para negociar con sus proveedores, $b$ ) mejorar su operación, c) aprovechar las economías de escala y mejoras tecnológicas y logísticas para aumentar la productividad. Esta alianza concluyó en 2008-2009 y coincidió con la crisis de Comercial Mexicana y la compra de Gigante por parte de Soriana. El resultado de ésta estrategia de adquisición permitió a Soriana entrar y posicionarse en el Distrito Federal, y colocarse como la segunda minorista a nivel nacional.

Otro ejemplo de alianza ocurrió en 1991, cuando Comercial Mexicana se asocia con Costco por medio de una Joint Venture, mediante la cual Costco operaría en el país, pero en el 2012 este acuerdo termina cuando la mexicana vende su participación a su contraparte. Ésta fue una estrategia que permitió de nuevo a una minorista extranjera, posicionarse en el mercado local.

En 1994 Carrefour hace lo mismo y establece una joint venture, ésta ocasión con Gigante, para luego, al igual que las otras minoristas extranjeras, adquirir la participación de la mexicana en dicha asociación. Sin embar- 
go, éste fue un caso especial, ya que en 2005 Grupo Chedraui compró a Carrefour todas sus sucursales en el país, como una estrategia de Carrefour para focalizar su actividad en sus principales mercados. Walmart por su parte, no detiene su crecimiento en el exterior en los siguientes años, entrando a nuevos países como Puerto Rico, Brasil, Canadá, China, Corea del Sur, Alemania, Reino Unido, Japón, Chile y Sudáfrica, con estrategias similares. Como dato importante, en 2009 Walmart de México, adquiere a Walmart Centroamericana, dando origen a Walmar de México y Centroamércia.

Las Fusiones y Adquisiciones (F\&A) en el mercado de minoristas han sido una estrategia clara de competencia y nos permite hacer algunas observaciones importantes:

- Las fusiones y adquisiciones son un método efectivo para entrar a un mercado desconocido para una empresa. El apoderarse de una empresa local, le permite a una empresa extranjera aprender del mercado $\mathrm{y}$ adaptarse, pues al adquirirla, adquiere las capacidades y un lugar en un mercado al que se llega por primera ocasión.

- Las fusiones y adquisiciones se convierten en un proceso de formación de redes nacionales con redes internacionales, lo cual le da ventajas competitivas a las empresas en términos de costos fijos (maquinaria equipo, organización, administración de personal, relaciones con proveedores), con lo cual se reducen los costos. Adicionalmente, se genera un mayor poder de negociación, y consiguiente explotación generalizada de la cadena de los proveedores, con el fin de presionar sus costos hacia abajo.

- Los procesos de fusiones y adquisiciones nos revelan un proceso de enfoque o redefinición de la actividad principal de una empresa. La unión de Cifra (Aurrera) con Wal-Mart finalmente se convirtió en un proceso de fusión por absorción, se asume la totalidad de los activos de la corporación mexicana. Sin embargo la empresa, más adelante se desharía de aquello que, aunque rentable, no es su actividad principal (acuerda la venta de la parte de restaurantes que se incluía en la compra de Cifra, a Alsea en el 2013 y se prevé la venta de Suburbia, una departamental especializada). En el caso de la compra de Gigante por Soriana, ésta sólo adquiere las tiendas Gigante, que eran parte de éste mercado al cual hemos llamado de minoristas, dejando las otras actividades del grupo Gigante fuera de la negociación, lo que le permitiría a ésta última enfocarse de mejor manera en un mercado al que habría de redefinir como el principal (redefine el centro de su actividad que ahora es el negocio inmobiliario, y tiendas especializadas en muebles para oficina), al abandonar el que antes ocupaba tal categoría, debido a la intensa competencia. Chedraui por su parte, adquiere las tiendas de Carrefour en el país, marcando la retirada de la competidora de Walmart a nivel mundial del mercado mexicano. Recientemente, Soriana ha adquirido las tiendas Comercial Mexicana (los formatos de Comercial Mexicana, Mega, Bodega Comercial Mexicana y Alprecio), lo que le permitirá a Controladora Comercial Mexicana enfocarse en sus formatos Premium.

\section{OS procesos de LOS fusiones y adquisiciones nos revelan un proceso de enfoque 0 redefinición de la actividad principal de una empresa}




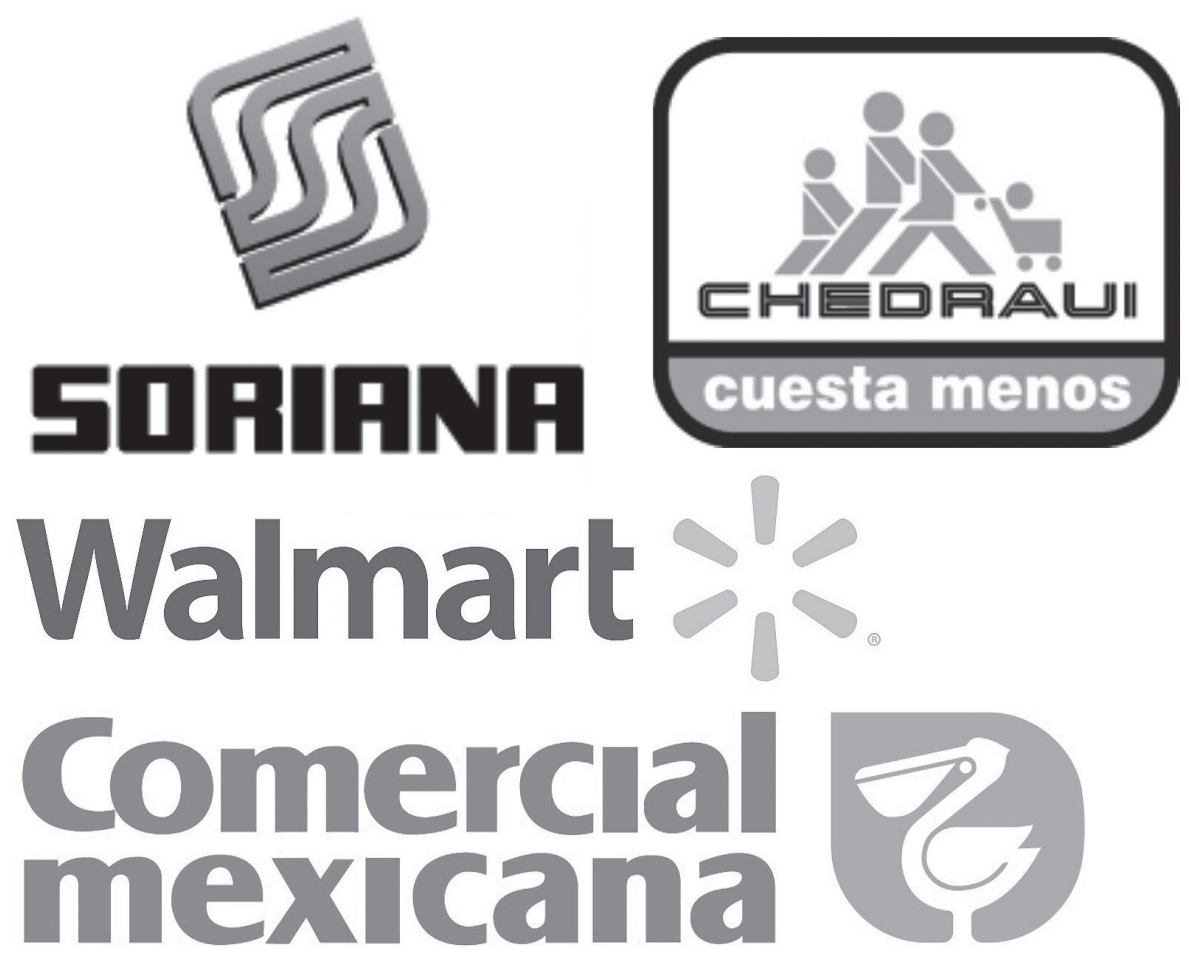

\section{Segmentación a través de formatos de tiendas}

Las empresas minoristas han elaborado un complejo esquema de competencia a través de distintos formatos de tiendas con el objetivo de segmentar el mercado de consumidores y obtener más ventas y ganancias. Esta estrategia de competencia por inversión la podemos calificar como de enfoque o segmentación no excluyente.

Esta estrategia de inversión en diferentes formatos de tiendas es sumamente compleja y costosa pero, en una sociedad con grandes desigualdades como la mexicana, y con muchos estratos de ingresos, esto les permite a las empresas obtener un mayor excedente económico. En los formatos para las clases altas se pueden vender productos de calidad superior con un margen de utilidad más alto. Esto no excluye que en esos formatos se encuentren productos estandarizados iguales para todos los segmentos y formatos, pero en cada formato el mismo producto puede tener diferente precio.

Por otro lado, las empresas desarrollan una estrategia de servicio al cliente diferente, donde los formatos para las clases altas ofrecen una infraestructura y un servicio más confortable para los consumidores. El criterio general, es que los formatos de tienda dirigidos a los estratos más altos cobren un precio mayor, y por tanto, sean más rentables. Esto es lo que podemos llamar: la lección City Market de Comercial Mexicana.

La estrategia de diferentes formatos resultó exitosa para Walmart por lo que las empresas seguidoras se ha movido en la misma dirección: buscaron crear diferentes formatos de tienda según el nivel de ingreso de la población objetivo. Este movimiento dinámico entre el líder y los seguidores se puede apreciar en el tiempo en los siguientes cuadros: 
Cuadro 2

Formato de tiendas de autoservicio en 2001

\begin{tabular}{|c|c|c|c|c|}
\hline $\begin{array}{l}\text { Sector o } \\
\text { Segmento }\end{array}$ & Walmart & Soriana & Comercial Mexicana & Chedraui \\
\hline Alto & Superama & & & \\
\hline Medio Alto & Sam`s Club & Soriana Hiper & & \\
\hline Medio & Bodega & & $\begin{array}{c}\text { Mega/Comercial } \\
\text { Mexicana }\end{array}$ & Tiendas Chedraui \\
\hline Medio Bajo & $\begin{array}{c}\text { Wal-Mart Supercen- } \\
\text { ter }\end{array}$ & & & Sùper Chedraui \\
\hline Bajo & & & Bodega Comercial & \\
\hline
\end{tabular}

Fuente: elaboración propia en base a la historia de cada una de las empresas e informes anuales de Wal-Mart de México en su página: http://www.walmex.mx/es/informacion-financiera/anual.html; Comercial Mèxicana:http://www.comerci.com.mx/index.php?option=com_content\&view=article\&id=90\&ltemid=52\&lang=esOrganizaciònSoriana:ht tp://www.sorianadomicilio.com/site/default.aspx?p=2946; Grupo Chedraui: http://chedrauiv4.random-interactive. com/index.php?r=site/rendercontent\&content=pages/historia

\section{Cuadro 3}

Formato de tiendas de autoservicio en 2014

\begin{tabular}{|c|c|c|c|c|}
\hline $\begin{array}{c}\text { Sector o } \\
\text { Segmento }\end{array}$ & Walmart & Soriana & Comercial Mexicana & Chedraui \\
\hline Alto & Superama & Soriana Plus & City Market & $\begin{array}{c}\text { Súper Selecto } \\
\text { Chedraui Selecto } \\
\text { Chedraui }\end{array}$ \\
\hline \multirow{4}{*}{ Medio } & Sam`s Club & City Club & & \\
\hline & & Soriana Hiper & $\begin{array}{c}\text { Alprecio Sumesa } \\
\text { Fresko }\end{array}$ & \\
\hline & Walmart Supercenter & $\begin{array}{c}\text { Soriana Mercado } \\
\text { Soriana }\end{array}$ & $\begin{array}{c}\text { Mega/Comercial } \\
\text { Mexicana }\end{array}$ & Tiendas Chedraui \\
\hline & Mi Bodega Aurrera & Soriana Súper & & Súper Chedraui \\
\hline Bajo & Bodega Aurrera & & Bodega Comercial & Súper Che \\
\hline $\begin{array}{l}\text { Tiendas de } \\
\text { conveniencia }\end{array}$ & $\begin{array}{c}\text { Bodega Aurrera } \\
\text { Express }\end{array}$ & $\begin{array}{c}\text { Super City Soriana } \\
\text { express }\end{array}$ & & \\
\hline
\end{tabular}

Fuente: elaboración propia en base a informes anuales de Wal-Mart de México en su página: http://www.walmex.mx/ es/informacion-financiera/anual.html; Formatos de Soriana en su página: http://www.sorianadomicilio.com/site/ default.aspx?p=9739; Formatos de Comercial Mexicana: http://www.comerci.com.mx/index.php?option=com_con tent\&view=article\&id=91\&ltemid=24\&lang=es; Formatos de Chedraui: http://www.grupochedraui.com.mx/index. php?r=site/rendercontent\&content=pages/grupo 
$\mathrm{W}$ almart se beneficia de su sistema masivo de distribución que le genera economías de escala y bajos costos, sin embargo, esto no ocurre en el mercado nacional

Walmart fue la primera empresa en introducir la estrategia de segmentación de mercado por ingreso dando lugar a diferentes formatos de tiendas. En 2001 Walmart poseía los formatos de Superama, Sam's club, Bodega Aurrera y Walmart Super Center. ${ }^{1}$

Las empresas rivales reaccionaron, en los años posteriores, replicando la misma estrategia. Para 2014 encontramos que las otras tiendas habían desarrollado formatos semejantes. Soriana fue la que más exitosamente replicó a Walmart y logró desarrollar los mismos formatos. Comercial Mexicana y Chedraui siguieron los mismos pasos pero no lograron desarrollar la misma estructura de formatos de tiendas.

Esta relación de dependencia entre los competidores también ha sido encontrada por otros investigadores como Tilly (Tilly, 2005, 2006), y Biles (Biles, 2006). Estos economistas han encontrado que esta relación de se-

1 El concepto de segmentación de mercado por nivel de ingreso es general y la usamos como una aproximación para explicar las estrategias de diferenciación de las minoristas pues refleja una intensionalidad de la tienda y el promedio de la gente que la visita. En la práctica una familia o consumidor que está en el estrato, por ejemplo, de nivel de ingresos medio puede asistir según su comodidad a cualquier formato de las tiendas Walmart. La libertad de compra mantiene abiertas sus puertas para cualquier persona con el solo hecho de que posea el medio de compra. guimiento también se presenta en el sistema de precios, innovaciones logísticas y procedimientos estandarizados.

Dentro de esta estrategia de segmentación del mercado, destaca que en los últimos años, las grandes empresas minoristas han desarrollado el formato de tiendas de conveniencia, en donde lo característico no es la segmentación por nivel de ingresos de la población, o la oferta de precios bajos, sino la conveniencia de cercanía de la tienda. En este caso las cadenas de minoristas compiten con otras cadenas y conglomerados como son Oxxo y 7 Eleven.

El segmento de tiendas de conveniencia posee una dinámica de oferta diferente a las minoristas que estamos estudiando, su forma de organización, y estrategias de expansión resultan diferentes con respecto a las grandes cadenas minoristas. La incursión en este segmento de Walmart y Soriana sólo ha sido parcial pues no se puede comparar con la expansión que tienen las tiendas Oxxo, y en menor medida 7-Eleven o Circulo K.

\section{Competencia de precios vía segmentación de mercado}

Podría pensarse que Walmart podría aplicar en el mercado local la misma estrategia de precios bajos que en su país de origen. El corazón del modelo de competencia de Walmart en Estados Unidos ha sido "operaciones de descuento (ganando utilidades por el gran volumen con un margen pequeño), alta tecnología logística, y poder de compra que se manifiesta en presión extrema sobre proveedores" (Tilly y Âlvarez, 2008). En efecto Walmart se beneficia de su sistema masivo de distribución que le genera economías de escala y bajos costos, sin embargo, esto no ocurre en el mercado nacional. 


\section{Cuadro 4}

Comparativo de la evolución de precios de las canastas elegidas por Sedeco entre tiendas minoristas (enero 2013-noviembre) 2014

\begin{tabular}{cccc}
\hline Canasta total & Soriana & Comercial M & Wal-Mart \\
\hline ene-13 & 2288.75 & 2375.93 & 2333.31 \\
ene-14 & 2325.73 & 2290.05 & 2408.40 \\
nov-14 & 2311.18 & 2399.27 & 2366.48 \\
\hline
\end{tabular}

Fuente: elaboración propia en base a cuadros 2, 3, y 4. http://www.sedecodf.gob.mx/archivos/Canasta\%20Basica/2013/ ENERO/3_CUADRO\%20COMPARATIVO\%20DE\%20PRECIOS\%20ENTRE\%20LOS\%20DIFERENTES\%20CANALES\%20 DE\%20DISTRIBUCION.pdf ; http://www.sedecodf.gob.mx/archivos/Canasta\%20Basica/2014/ENERO/3_CUADRO\%20COMPARATIVO\%20DE\%20PRECIOS\%20ENTRE\%20LOS\%20DIFERENTES\%20CANALES\%20DE\%20DISTRIBUCIO: N.pdf ; http://www.sedecodf.gob.mx/archivos/Canasta\%20Basica/2014/NOVIEMBRE/3_CUADRO_COMPARATIVO_DE_PRECIOS_ENTRE_LOS_DIFERENTES_CANALES_DE_DISTRIBUCION.pdf

La estrategia de precios aplicada a la economía mexicana es diferente a la aplicada en Estados Unidos. La estrategia de Walmart se ha orientado a las clases medias vía servicios al cliente, más que atraerlos por los precios bajos. En este sentido, los resultados apoyan la idea de que las multinacionales modifican sus estrategias de acuerdo a las condiciones de los mercados en que participan, según la cultura y las instituciones de cada país (Almond, 2007).

\section{Análisis de precios: precios estratégicos}

En esta estructura de mercado donde existen cuatro grandes oferentes y millones de consumidores, los precios no se fijan por el libre juego de la oferta y la demanda. Se puede asumir que las empresas fijan el precio. ${ }^{2}$

2 Si el precio de los mismos productos en el mercado es único, podemos decir que existe competencia perfecta, una pequeña variación de estos llevaría la demanda a la empresa con el menor precio. En contraposición, si los precios son diferentes, y con forme los precios sean más diferentes podemos decir que no existe competencia de precios.
La Secretaria de Desarrollo Económico (Sedecof) hizo un listado de algunos productos con los cuales formó una canasta de bienes y elaboró el comparativo de precios en los diferentes tiendas minoristas. Dentro de esta cesta se encuentran diversos productos como cereales, granos, frutas, verduras, cárnicos, abarrotes y artículos para el hogar y la limpieza.

Del cuadro anterior podemos concluir que: existe una diferencia de precios en la canasta seleccionada por esta secretaría, esta ronda los cien pesos lo que corresponde a un porcentaje algo menor a 5\%. Se puede decir que la competencia que existe entre ellas las lleva a fijar precios muy parecidos. ${ }^{3}$ Sin embargo, esta no es una competencia perfecta sino de carácter oligopólico, Por lo que le podemos calificar de competencia estratégica de precios entre oligopolios.

Algo que destaca de éste análisis es que la empresa líder no por ser la más grande y con una red de compra-venta más sofisticada tiene los precios más bajos, en este sentido la publicidad se convierte en una forma de competencia muy poderosa. Para hacer pensar a los

3 Al respecto estamos suponiendo que la forma en que se eligió la canasta de productos, el levantamiento de precios y el cálculo es correcto. 
consumidores que Walmart da los precios más bajos. En los comparativos de precios en diferentes productos encuestados, los mercados sobre ruedas son los que reportan los precios más bajos, esto explica su sobrevivencia en un entorno oligopólico como el que estamos mencionando.

Se logra encontrar además que la forma de fijar los precios de la segunda seguidora, Chedraui, le permite mantenerse en el mercado y ser la que tiene precios más bajos. A esta forma de fijar precios se puede denominar fijación estratégica de precios o sobrevivencia ante la competencia en el oligopolio.

En el informe anual de Chedraui de 2010 afirman: "estamos verdaderamente comprometidos con ofrecer todos los días los precios más bajos en cada producto que vendemos. Se requiere un gran esfuerzo para comparar precios y la capacidad de responder rápidamente. Realizamos aproximadamente 1900 ajustes de precios diariamente a nivel centralizado y los gerentes de las tiendas llevan a cabo otros 85000 ajustes con base en los competidores locales. Nuestros clientes saben que lo hacemos y esto genera su lealtad" (Informe anual Chedraui, 2010, p. 8). ${ }^{4}$ En resumen, la estrategia de Chedraui es ir a las empresas rivales a observar los precios de la competencia y entonces fijar un precio inferior. Por lo cual podemos calificar a este procedimiento como la fijación de precios estratégica de sobrevivencia. Esto es posible gracias al gran margen de ga-

4 Esta forma de fijación de precios de sobrevivencia, la empresa Chedraui lo expresa de la siguiente forma: "Para garantizar el precio más bajo, día a día realizamos chequeos de mercado en tiendas de nuestros competidores, tanto a nivel local como central y sobre una variada gama de productos. A través de estas revisiones nuestros clientes pueden tener la seguridad de que en Chedraui están encontrando el mejor precio, sin importar su ubicación o la sucursal que visiten" (informe anual Chedraui, 2014, p. 11). nancia que las cadenas comerciales minoristas poseen muy por encima del que obtienen los vendedores de los mercados sobre ruedas.

En cuarto lugar, como resultado de la integración empírica en varios formatos de tiendas encontramos que existen diferencias en los precios de los mismos productos, relacionados a: 1. Entre las cadenas de minoristas, y 2. En la misma empresa, los precios cambian entre los formatos de tiendas, 3. En las mismas empresas los precios cambian por zona geográfica, 4. Al considerar las empresas, lo más complejo de todo es que los precios cambian por temporada y la tienda con precios más altos cambian en algunos productos reporta precios bajos en otra temporada. En una temporada del año la cadena con precios altos de artículos básicos como cereales y granos reportan los más bajos en productos hortofrutícolas, y así sucesivamente con los cárnicos, y esta relación cambia en el tiempo. A la complejidad para conocer los precios, por tipo de producto y por cadena de minorista, se agrega el hecho de que las corporaciones fijan precios diferentes a los mismos productos dependiendo de los formatos de tiendas. En este caso, la empresa, en general, fija un precio mayor a los formatos para los deciles con mayores ingresos. Lo anterior

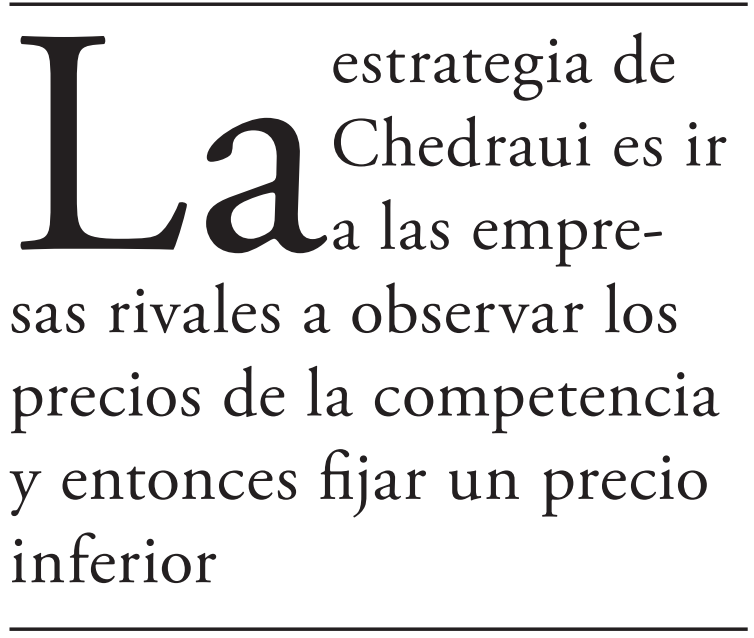


hace casi imposible para el consumidor saber a ciencia cierta cuál es la cadena de minorista $\mathrm{y}$ en que formato puede encontrar los precios más bajos.

Por tanto, la elección del consumidor de dónde comprar su canasta de consumo es sumamente compleja y la información que conoce no le permite tomar una decisión basada en precios. El consumidor decide dónde y cuánto comprar por otros criterios, como sus necesidades, su ingreso, restricción de tiempo, publicidad y propaganda, la distancia, conveniencia, comodidad, servicio al cliente y estatus.

Otros estudios refuerzan los resultados anteriores. Tomando datos de la Procuraduría Federal del Con-

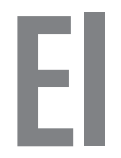
consumidor decide dónde y cuánto comprar por criterios como sus necesidades, su ingreso, restricción de tiempo, publicidad y propaganda, la distancia, conveniencia, comodidad, servicio al cliente y estatus sumidor (Profeco), de

"Quién es Quién en los precios", se hizo un listado de algunos productos y se hizo el comparativo de precios en los diferentes formatos de las distintas tiendas de las minoristas. ${ }^{5}$

Según los datos analizados, dependiendo del formato, la misma empresa vende un mismo producto a diferentes precios, elevándolo a medida que sube dentro de su escala de estratificación.

Los precios en los formatos dirigidos a estratos socioeconómicos más bajos, reportan una diferencia, entre empresas rivales, mucho

5 Los productos seleccionados fueron: Agua, Café soluble, Aceite, Atún, Detergente para ropa y para trastes, tomado las tiendas que se tenían disponibles en la base de datos de la Profeco para el Distrito Federal y su área metropolitana en fechas de la semana que va del 22 al 29 de septiembre del 2014. (http://www.profeco.gob.mx/precios/canasta/home.aspx?th=1) menor (variando de 2 a 3 pesos) que en los estratos más altos en donde, además de una diferencia mayor, es bastante claro que la líder, con precios más bajos en casi todos los otros productos, incluso los coloca por encima de los de la competencia.

Esto nos da un claro indicio de que una de las estrategias de competencia en los formatos dirigidos a estratos socioeconómicos bajos es el precio, ya que las minoristas cuidan tanto ésta variable, que existe una diferencia muy pequeńa con respecto a la competidora más cercana. En cambio, en los estratos socioeconómicos altos, la variación es mayor, lo que implicaría que el precio, además de un filtro para clientes de menor poder adquisitivo, no representa un criterio para competir. Variables como el diseño, acomodo de los pisos de venta, los productos que se ofrecen, la calidad de los mismos, su variedad y la atención al cliente, tienen más peso que el precio dentro de la estrategia de competencia.

\section{Innovación en servicios financieros}

La introducción de innovaciones financieras y la reacción de las empresas en este mercado, reflejan la interdependencia entre las mismas. Este es el caso de la introducción de tarjetas de crédito como servicio a los clientes de las cadenas minoristas (véase cuadro 5). 
La primer empresa que lanzó la iniciativa de tarjeta de crédito fue la líder Walmart. Tras la autorización de la creación de Banco Walmart, las empresas locales reaccionaron de inmediato: Chedraui y Comercial Mexicana fueron las primeras en hacerlo, sin embargo, fue la Comercial Mexicana quién, mediante un acuerdo con una empresa de origen francés, especializada en créditos al consumo, lanzó la primer tarjeta de crédito "Plasticomer" al mercado, incluso antes que la líder. Chedraui buscó crear una institución financiera a la que denominó Banco Fácil, quién recibió la autorización de las autoridades solo unos meses después de la autorización de Banco Walmart, iniciando operaciones en febrero del siguiente año. Soriana fue quién tardó más en consolidar la idea, al anunciar el acuer- do que habría de firmar con Banamex para emitir la tarjeta de Crédito Soriana. A pesar de haber sido el primera en recibir la autorización, Banco Walmart iniciaría operaciones en octubre del 2007.

Esta estrategia tuvo resultados no esperados para algunas de las minoristas. En 2014 Banco Walmart, después de reportar constantes pérdidas fue adquirido por Grupo Financiero Inbursa. Caso similar enfrentó Chedraui con Banco Fácil, el cual sufrió una fuerte crisis de cartera vencida, sin embargo, se le dio nueva vida mediante su fusión con la Sofol Consupago en 2009, del mismo grupo, por lo que se le permitió seguir operando. Las empresas que se asociaron con expertos especializados en el ramo, como el caso de Comercial Mexicana

Cuadro 5

Salida de las Innovaciones en Tarjetas de Crédito de las Minoristas en México

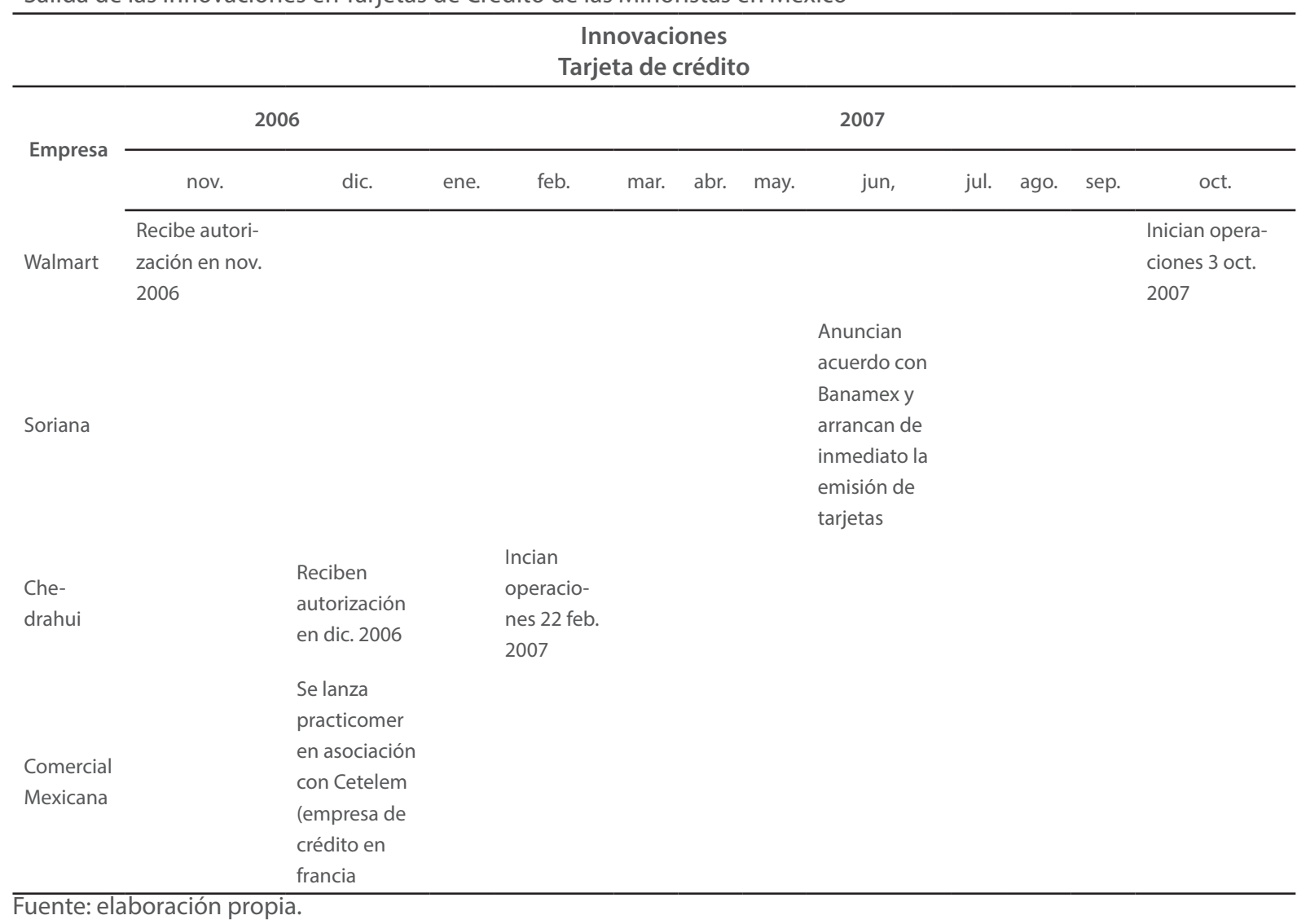


(Cetelem) y Soriana (Banamex), no presentaron problemas financieros con su nuevo producto.

Éste es un ejemplo de cómo las empresas reaccionan ante las acciones de las otras, forzando a realizar inversiones o generar estrategias para no ser excluidas del mercado, también es una lección de que las estrategias y métodos usados por la líder no son siempre acertadas. En este caso las decisiones de las seguidoras resultaron apropiadas.

\section{Líneas futuras de investigación}

El análisis presente abarca tan sólo un pequeño universo de las tiendas de ventas al menudeo, existen al menos dos grandes grupos de tiendas que requieren ser estudiadas: las tiendas departamentales especializadas y las tiendas de conveniencia, cada una de ellas con interesantes estrategias que merecen ser abordadas.

\section{Conclusiones}

En las últimas décadas, el mercado mexicano se ha caracterizado por el boom y dominancia de las tiendas de autoservicio. Esto ha coincidido con la llegada de Walmart y la competencia que hemos analizado en el mercado de minoristas.

El mercado mexicano de empresas minoristas se caracteriza por ser claramente oligopólico. La competencia revela todo el poder de las megacorporaciones nacionales e internacionales involucradas.

La forma dominante de competencia es la de inversión. La competencia puede ser dividida según su horizonte temporal: en el lar- go plazo la competencia es de inversión en al menos tres formas: a) Fusiones, adquisiciones y alianzas estratégicas $b$ ) superficie y unidades de ventas, y c) la segmentación del mercado a través de diferentes formatos de tiendas no son excluyentes para los consumidores, pero que están enfocadas en un estrato socioeconómico determinado. En el corto plazo, pudimos identificar una forma de competencia estratégica de precios y no precios, destaca y estrategias de innovación financiera, de organización, de distribución y logística. Tanto las formas de competencia de largo como de corto plazos se han traducido en un proceso de crecimiento y concentración continuo.

En el proceso de fijación de precios encontramos la estrategia que hemos calificado como de precios estratégicos de competencia y fijación de precios para la sobrevivencia, esta última aplicada por Chedraui.

$\mathrm{La}$ interdependencia es una característica de los mercados oligopólicos, y en el mercado de minoristas la pudimos constatar en las diferentes formas de competencia. Los movimientos de una serán seguidos por las otras, intentando copiar estrategias, independientemente si son estrategias exitosas o no, pues el costo por no intentarlo podría ser mucho mayor al costo por hacerlo en términos de participación en el mercado.

Las innovaciones son una forma más en la que las minoristas compiten en México: es el caso de los formatos de tiendas, las tarjetas de crédito y sistemas de informática. Algunas estrategias son exitosas, otras no, la competencia y el mercado lo decidirá.

Finalmente, la conclusión más importante es que la competencia en los mercados oligopólicos, particularmente en el mercado de las grandes empresas minoristas, es compleja; se adapta y evoluciona en el tiempo. ? 
Gustavo Vargas Sánchez | Carlos Mario Rodríguez Peralta |

Oligopolio y estrategias de competencia en el mercado de minoristas en México

\section{Referencias}

Almond, Phil, 2007, Managing pay and performance in Usbased multinationals: A look at subsidiariaries in the United Kingdom" Perspectiveson Work, Summer, 7-9.

Andrews, P. W. S. (1959), Economia de las empresas Industriales, Buenos Aires: Santiago Rueda, Editor.

Chandler, Alfred (1969), Strategy and Structure, The MIT Press, Estados Unidos.

Eichner, Alfred (1988), Toward a New Economics, Essays in Post-Keynesian and Institutionalist Theory, New York: M.E. Sharpe, chapter 3.

Kaplinsky, Raphael (2005), Globalization, Poverty and Inequality. Polity Press. London, England.

Lavoie, Marc (1992), Foundations of Post-Keynesian Economic Analysis, Cheltenham: Edward Elgar.

Lee, Frederic (1988), Post Keynesian Price Theory, United Kingdom: Cambridge University Press.

Schumpeter, Joseph A. (1912), Teoría del desenvolvimiento económico, México: Fondo de Cultura Económica, Primera edición en español, 1944.

Labini, Sylos P. (1966), Oligopolio y progreso técnico, Barcelona: Ediciones Oikos-tau.

Labini, Sylos P. (1988), Las Fuerzas del Desarrollo y del Declive, Barcelona: Oikos-Tau.

Penrose E. (1958) Teoría del crecimiento de la Empresa. Ugarte, Jesús (2015), "Soriana compra 160 tiendas de La Comer por 39,194 mdp" Periódico El financiero. http://www.elfinanciero.com.mx/empresas/acuerdan-venta-de-comercial-mexicana-a-soriana-por39-194-mdp.html

Tilly, C. , Alvarez J. (2008), "El tamaño sí importa: Monopolio, el monopsonio y el impacto de WalMart en México", Economía Informa, 351, marzoabril de 2008.

Tilly, Chris (2006) Walmart goes south: Sizing up the chain's Mexican success story, en stanley Brunn, coord., Wal- Mart world, New York: Routledge.

Tilly, Chris (2005), Wal-Mart in Mexico: The limits of growth, en Nelson Lichtenstein, coord., Wal-Mart: the face of 21st Century Capitalism. New York: New Press

Vargas, Gustavo (2006a), Teorías de la Empresa y de la Competitividad, México: Editorial Castdel.

Vargas, G. (2006b), Introducción a la Teoría Económica, un enfoque latinoamericano, México: Editorial Pearson Educación

\section{Lecturas adicionales sugeridas}

Corona, Leonel (2012), “Innovar la innovación. Evolución y perspectivas de los conceptos de innovación y emprendedor”, X Congreso Nacional de la RIDIT, Toluca, México.

Harcourt, G. y Peter Kenyon (1988), "La fijación de precios y la decisión de inversión”, en, Ocampo, José Antonio (1988), Economía Poskeynesiana, Lecturas del Trimestre Económico núm. 60, México: FCE, capítulo 9.

Koutsoyiannis, Anna (1988), Non-Price Decisions, Hong Kong: McMillan Education.

Hall, R. L. y Hitch, C. J. (1939) "Price Theory and Business Behaviour", Oxford Economic Papers, Vol. 2 (1), pp. 12-45.

Pindyck, Robert S. y Rubinfeld, Daniel L. (2001), Microeconomía, 5a Edición, Pearson- Prentice Hall.

Samuelson, Paul y D. Nordhaus (2010), Microeconomía con aplicaciones a Latinoamérica, Decimonovena edición, México: Mac Graw Hill.

Varian, Hal R. (2011), Microeconomía intermedia, $8 a$ edición, Antony Bosch Editor.

Vargas, Gustavo (2006), Teorías de la Empresa y de la Competitividad, México: Editorial Castdel. 